\title{
OBSERVING DRUG UTILIZATION TRENDS OF ANALGESICS IN INDOOR SURGICAL PATIENTS IN TERTIARY CARE TEACHING HOSPITAL
}

\author{
VIDISHA VIVEK PARULEKAR*, VANDANA AVINASH BADAR
}

Department of Pharmacology, Indira Gandhi Government Medical College, Nagpur, Maharashtra, India. Email: dr.vidishaparulekar@gmail.com Received: 01 February 2020, Revised and Accepted: 04 March 2020

\begin{abstract}
Objectives: The objectives of the study were to evaluate and compare the utilization pattern of analgesic use in pre-operative, intraoperative, and post-operative wards of different surgical specialties.

Methods: It was a prospective, cross-sectional, and observational study done for a period of 1 year and the data were obtained from case sheets of 386 patients admitted in surgical wards of the. Data were analyzed according to demography, type of surgery, and the WHO prescribing indicators. The percentage of analgesic prescribed from an essential medicine list or National list of essential medicine (NLEM), common analgesics, and fixed dose combinations (FDC) used in surgery, gynecology, ENT, and orthopedic wards in preoperatively, intraoperatively, and postoperatively, was assessed and the amounts of drugs consumed were converted into the number of daily defined dose (DDD) as per the 2010 version of ATC/DDD index.

Results and Discussion: The female to male ratio of 1.21 and most of patients were in the category of middle-aged adults (49\%). On the evaluation of WHO prescribing parameters, it was seen the average number of analgesics prescribed per prescription was 1.26 , percentage of injectable analgesics and analgesics prescribed from NLEM were $81.09 \%$ and $90.64 \%$, respectively. Perioperatively, injection diclofenac sodium was the most commonly used analgesic and its DDD was 460. The most common FDC used perioperatively was aceclofenac $325 \mathrm{mg}+$ serratiopeptidase 15 mg ( $5.04 \%$ ) and Drug Controller General of India and the WHO approved FDCs were $80.28 \%$ and $75.53 \%$, respectively.
\end{abstract}

Conclusion: It is necessary to determine the prevalence and severity of post-surgical pain and implementation of standardized pain evaluation and treatment protocols which improve the post-operative patient care in the hospital setting.

Keywords: Analgesics, Fixed dose combinations, WHO prescribing parameters, National list of essential medicines, Daily defined dose.

(C) 2020 The Authors. Published by Innovare Academic Sciences Pvt Ltd. This is an open access article under the CC BY license (http://creativecommons. org/licenses/by/4. 0/) DOI: http://dx.doi.org/10.22159/ajpcr.2020.v13i5.37062

\section{INTRODUCTION}

Post-operative pain is one of the end results of any surgical procedure and calls for efficient management. The task force on taxonomy of the international association for the study of pain defines pain as, an unpleasant sensory and emotional experience associated with actual or potential tissue damage [1]. Optimizing pain management can improve the outcome of patient care after any surgical intervention.

Inadequate pain control can result in increased morbidity and length of hospital stay as well as increasing risk of persistent post-operative pain. Persistent post-surgical pain lasts beyond typical healing period of 1-2 months, has become increasingly recognized as a significant issue after surgery and may exceed $30 \%$ after certain operations particularly, amputations, thoracotomy, mastectomy, and inguinal hernia repairs [2]. It can also lead to complications such as deep vein thrombosis, atelectasis, and also delayed wound healing. Multimodal pain management combines the use of various pharmacological mechanisms of action and additive or synergistic effects, which work by acting at different sites within central and the peripheral nervous system [3]. Hence, the use of procedure specific, multimodal pain management has almost become mandatory following surgery to enhance post-operative recovery.

The other concern in inadequate pain relief is the fear of the possibility of the development of physical dependence, tolerance, and addiction with the use of opioid analgesics. Undertreated severe pain may have physiological consequences increasing the stress response to surgery, seen as a cascade of endocrine-metabolic and inflammatory events that ultimately may contribute to organ dysfunction, morbidity, increased hospital stay, and mortality. It may lead to several complications related to major systems such as cardiovascular, respiratory, gastrointestinal, musculoskeletal, thromboembolic, and also psychological [3].

According to the recent CDC report, non-opioid therapy is preferred for the treatment of chronic pain [4]. In case of severe post-operative pain, nonsteroidal anti-inflammatory drugs (NSAIDS) alone are not adequately sufficient to control the post-operative pain. When used in combination with opioids, NSAIDS decrease opioid related side effects such as nausea, vomiting, and sedation [5]. Large varieties of analgesics are available in the market which may lead to the problem of irrational prescription. The study of prescribing pattern is a significant constituent of medical audit which helps in monitoring, evaluating, and building required modifications in the prescribing practices to attain a rational and cost effective medical care [1,6-8]. Therefore, the present study aims at evaluating and comparing the utilization pattern of analgesic use in pre-operative, intraoperative, and post-operative wards of different surgical specialties.

\section{METHODS}

The surveillance study of analgesics in major surgical patients in tertiary care teaching hospital was conducted as prospective crosssectional observational study. The study subjects were all patients admitted to the wards in the study duration. The study did not involve any interview of the patients admitted. The data were collected time to time from all the medical records of the patient with respect to details of analgesic therapy administered to the patients.

The Institutional Ethics Committee approval and well informed written consent were taken from all the cases included in the study. The incharge authority of surgical departments was notified and permission 
was taken. The inclusion criteria were age of $>18$ years, of either gender, patient undergoing major surgeries, patient receiving in-patient care in the departments of surgery, gynecology, orthopedics, and ENT, patients having comorbidities such as diabetes, hypertension, malnutrition, COPD, TB, HIV, obesity, smoking, and alcohol abuse. The exclusion criteria were minor surgical cases, pregnancy and lactation, medicolegal, patient receiving in-patient care in cardiothoracic, ophthalmic, neurosurgical, pediatric surgical, obstetrics departments, postoperative deaths before discharge, patient who absconded/discharged against medical advice, patient referred to other hospitals, incomplete data were excluded from the study.

The data were obtained from 386 patients admitted in surgical wards of the hospital from the period of February 2017 to February 2018, i.e., 1 year. Data were analyzed according to the demography, type of surgery, and the WHO prescribing indicators. The percentage of analgesic prescribed from an essential medicine list (EML) or national list of essential medicine (NLEM) was assessed with following formula

$$
\text { Percentage calculated }(\%)=\frac{\begin{array}{c}
\text { No. of products prescribed which } \\
\text { areinessential drug list }
\end{array}}{\text { Total number of drugs prescribed }} \times 100
$$

Analgesics prescribed during peri-operative period, percentage of analgesics used as generic drugs, branded drugs, fixed dose combinations (FDCs), and Drug Controller General of India (DCGI) approved FDCs was also analyzed. From the prescription data of commonly prescribed groups of drugs, the amounts of drugs consumed were converted into the number of daily defined dose (DDD) as per the 2010 version of ATC/DDD index [9].

\section{Statistical analysis}

Data were collected and compiled using Microsoft Excel 2010 and then analyzed by calculating simple proportions, frequency, and percentage. The sample size was calculated using software OpenEpi, Version 3, open source calculator with the prevalence as $50 \%$, power $95 \%$ with $5 \%$ error.

\section{RESULTS}

In our study, 386 patients were followed up until the post-operative period. It was observed that female patients (55.69\%) were more than male (44.60\%) patients with a female to male ratio of 1.21 .

The age-wise distribution of data was categorized into four mainly young adults (18-35 years), middle-aged adults (36-55 years), old adults (56-65 years), and geriatrics ( $>65$ years). It was seen that the majority of patients were in the category of middle-aged adults (49\%), followed by young adults (34\%), as shown in Fig. 1.

In Fig. 2, department-wise distribution of data is shown. Four departments were involved in the study. The majority of the cases were taken from wards of general surgery department (43\%).

Abdominal surgeries were in majority (24.61\%) (Table 1) which included exploratory laparotomies, laparoscopic appendectomies, and laparoscopic cholecystectomies. Gynecology surgeries predominated constituted of total abdominal hysterectomies, non-descent vaginal hysterectomies, myomectomies, hysteroscopic dilatation, and curettage.

On the evaluation of the WHO prescribing parameters, it was seen the average number of analgesics prescribed per prescription was 1.26. The percentage of analgesics prescribed by generic name was $79.56 \%$. The percentage of injectable analgesics was $81.09 \%$. The percentage of AMA prescribed from NLEM was $90.64 \%$, as shown in Tables 2-4.

Table 5 shows DDD of three most common analgesics prescribed in this study.

\section{DISCUSSION}

In this study, a total of 386 patients were observed during the course of their surgical treatment of a tertiary teaching care hospital for over 1 year. The patients were admitted for various diagnoses such as acute appendicitis, acute cholecystitis, acute tonsillitis, uterine myomas, dysfunctional uterine bleeding, fractures, and osteoarthritis. According to the demographic data, male to female ratio is 0.82 as oppose to Arshad et al. [10] where it was 0.53. This is due to the inclusion of cases operated in the department of gynecology. The average

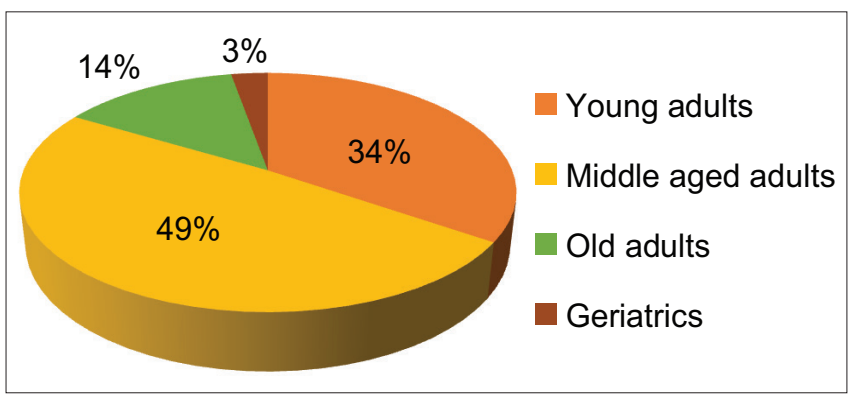

Fig. 1: Age-wise distribution of data

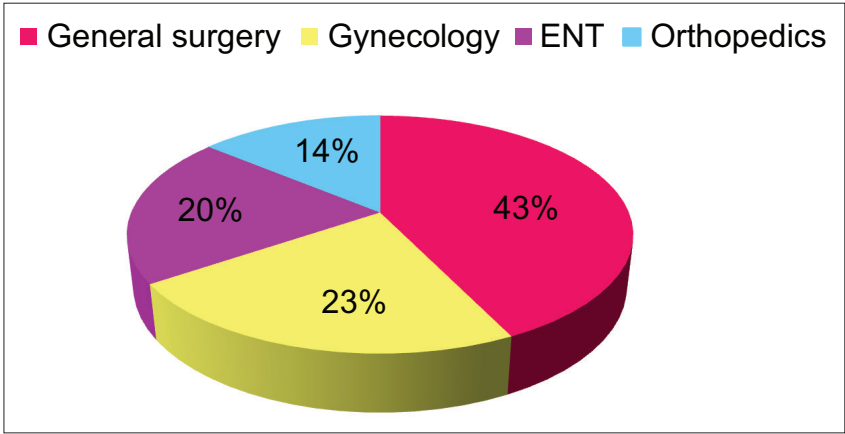

Fig. 2: Department-wise distribution of data

Table 1: Type of surgery $(n=386)$

\begin{tabular}{lll}
\hline Type of surgery & No of patients & Percentage of patients \\
\hline Abdominal surgery & 95 & 24.61 \\
Gynecology surgery & 88 & 22.79 \\
Head-and-neck surgery & 79 & 20.46 \\
Musculoskeletal surgery & 54 & 13.98 \\
Rectal surgery & 26 & 6.73 \\
Hernia repair surgery & 18 & 4.66 \\
Scrotal surgery & 12 & 3.10 \\
Urological surgery & 10 & 2.59 \\
Breast surgery & 4 & 1.03 \\
\hline
\end{tabular}

Table 2: WHO prescribing parameters

\begin{tabular}{ll}
\hline WHO parameters & Frequency \\
\hline $\begin{array}{l}\text { Total analgesic drugs prescribed } \\
\text { Percentage of analgesic used by generic name/ }\end{array}$ & 1518 \\
prescription & $79.56 \%$ \\
$\begin{array}{l}\text { Average number of drugs/prescription } \\
\text { Average number of analgesics/prescription }\end{array}$ & 4.84 \\
$\begin{array}{l}\text { Percentage of analgesic prescribed for intravenous } \\
\text { route }\end{array}$ & 1.26 \\
$\begin{array}{l}\text { Percentage of analgesics prescribed from essential } \\
\text { medicine list }\end{array}$ & $18.09 \%$ \\
$\begin{array}{l}\text { Percentage of analgesics prescribed from national list } \\
\text { of essential medicine }\end{array}$ & $90.84 \%$ \\
$\begin{array}{l}\text { Average duration of surgical intensive care unit stay } \\
\text { Average duration of hospital stay }\end{array}$ & 5.26 \\
\hline
\end{tabular}


Table 3: Analgesics prescribed at pre-operative stage $(n=471)$

\begin{tabular}{lll}
\hline Analgesic & $\begin{array}{l}\text { No of } \\
\text { analgesics } \\
\text { prescribed }\end{array}$ & $\begin{array}{l}\text { Percentage } \\
\text { of analgesics } \\
\text { prescribed }\end{array}$ \\
\hline inj.diclofenac $50 \mathrm{mg}$ & 160 & 33.97 \\
inj.diclofenac $75 \mathrm{mg}$ & 75 & 15.92 \\
inj.paracetamol 1 g & 38 & 8.06 \\
inj.pentazocine $30 \mathrm{mg}$ & 4 & 0.84 \\
inj.pentazocine $100 \mathrm{mg}$ & 16 & 3.39 \\
inj.tramadol $100 \mathrm{mg}$ & 77 & 16.34 \\
T.Brufen (ibuprofen) $400 \mathrm{mg}$ & 22 & 4.67 \\
T.diclofenac 50 mg & 50 & 10.61 \\
T.diclofenac 75 mg & 13 & 2.76 \\
*T.Emagen (diclofenac 50 mg + & 8 & 1.67 \\
serratiopeptidase 10 mg) & & \\
T.pentazocine 50 mg & 4 & 0.84 \\
T.tramadol 100mg & 4 & 0.84 \\
\hline
\end{tabular}

\begin{tabular}{lcc}
\hline \multicolumn{3}{l}{ Analgesics prescribed at intraoperative stage $(\mathbf{n = 4 8 8})$} \\
\hline ini.diclofenac50 mg & 125 & 25.61 \\
ini.diclofenac $75 \mathrm{mg}$ & 134 & 27.45 \\
inj.fentanyl $150 \mathrm{ug}$ & 20 & 4.09 \\
inj.paracetamol $1 \mathrm{~g}$ & 149 & 30.53 \\
inj.pentazocine $30 \mathrm{mg}$ & 12 & 2.45 \\
inj.pethidine $100 \mathrm{mg}$ & 4 & 0.81 \\
inj.tramadol $100 \mathrm{mg}$ & 32 & 6.55 \\
T.diclofenac $50 \mathrm{mg}$ & 8 & 1.63 \\
T.paracetamol $500 \mathrm{mg}$ & 4 & 0.81 \\
\hline
\end{tabular}

Analgesics prescribed at post-operative stage $(n=559)$

\begin{tabular}{|c|c|c|}
\hline inj.diclofenac $50 \mathrm{mg}$ & 121 & 21.7 \\
\hline inj.diclofenac $75 \mathrm{mg}$ & 94 & 16.9 \\
\hline inj.paracetamol $1 \mathrm{~g}$ & 120 & 21.6 \\
\hline inj.pentazocine $30 \mathrm{mg}$ & 28 & 5.04 \\
\hline inj.pentazocine $100 \mathrm{mg}$ & 12 & 2.16 \\
\hline inj.tramadol $50 \mathrm{mg}$ & 4 & 0.72 \\
\hline inj.tramadol 100 mg & 114 & 20.52 \\
\hline T.diclofenac $50 \mathrm{mg}$ & 84 & 15.12 \\
\hline T.diclofenac $75 \mathrm{mg}$ & 8 & 1.44 \\
\hline $\begin{array}{l}\text { *T.Emagen (diclofenac } 50 \mathrm{mg}+ \\
\text { serratiopeptidase } 10 \mathrm{mg} \text { ) }\end{array}$ & 4 & 0.72 \\
\hline T.pentazocine $30 \mathrm{mg}$ & 3 & 0.54 \\
\hline $\begin{array}{l}\text { *T.Fortagesic (T.pentazocine } 15 \mathrm{mg}+ \\
\text { paracetamol } 500 \mathrm{mg} \text { ) }\end{array}$ & 16 & 2.88 \\
\hline $\begin{array}{l}\text { *T.Zerodol SP (T.aceclofenac } 325 \\
\text { mg+serratiopeptidase } 15 \mathrm{mg} \text { ) }\end{array}$ & 28 & 5.04 \\
\hline
\end{tabular}

Table 4: Use of generic drugs, branded drugs, and fixed dose combinations $(\mathrm{n}=1518)$

\begin{tabular}{lll}
\hline Drugs & Number & Percentage \\
\hline Generic drugs & 1213 & 79.89 \\
Branded drugs & 305 & 20.10 \\
Fixed dose combinations & 209 & 13.76 \\
$\begin{array}{l}\text { Fixed dose combinations approved by } \\
\text { drug controller general of India }\end{array}$ & 1214 & 80.28 \\
$\begin{array}{l}\text { Fixed dose combinations approved by the } \\
\text { WHO }\end{array}$ & 1146 & 75.53 \\
\hline
\end{tabular}

Table 5: ATC-DDD classification

\begin{tabular}{llll}
\hline Drug & ATC & WHO & No. of DDD \\
& CODE & recommended DDD & \\
\hline Inj.diclofenac 50 mg & M01AB05 & $0.1 \mathrm{~g}$ & 460 \\
Inj.tramadol 100 mg & N02AX02 & $0.3 \mathrm{~g}$ & 278.6 \\
Inj.paracetamol 1 g & N02BE01 & $3 \mathrm{~g}$ & 313.3 \\
\hline
\end{tabular}

ATC: Anatomical therapeutic chemical, WHO: World Health Organization, DDD: Daily defined dose age was 41.84 years and the most common age group was middleaged adults (36-55 years) with $49 \%$. This finding of our study was consistent with the study by Min et al. [11] where maximum number of patients (68.3\%) was in age group of $40-70$ years. Similar results were also seen in the Bhataia et al. [8] and Khan et al. [12] study. This is the usual trend as this is the productive age group and is actively involved in socioeconomic activities, which may lead to stress and age factor making them vulnerable to diseases that may need surgical interventions [1]. The maximum number of cases was taken from wards of general surgery department (43\%), followed by gynecology (14\%) department. However, Barawade and Gursale [13] in their study collected maximum cases from gynecology (48.61\%), followed by surgery $(25 \%)$ department.

According to the WHO prescribing parameters, total drugs prescribed were 1518. The majority of analgesics were prescribed by generic name $(79.56 \%)$. This finding is consistent with Bhataia et al. [8] where 5627 total medicine formulations were studied and 98.51\% (5534) were found out to be prescribed by official/generic names. Similarly, in Agrawal et al. [14] study, $77.77 \%$ drugs were prescribed by generic name. Contrary to our study, $48.57 \%$ drugs were prescribed by generic name in the Bhansali et al. study [4]. The percentage of drugs prescribed by generic name according to the WHO standard should be $100 \%$. Increasing generic prescribing would rationalize the use and reduce the cost of drugs [14]. It also reduces confusion while prescribing.

In our study, the average number of drugs/prescription was 4.8. This was significantly less compared to Bhataia et al. [8] and Bhansali et al. [15] study where maximum patients received eight drugs/prescription. Reference values of 1.6-1.8 drugs per prescription are recommended by the $\mathrm{WHO}$ guidelines on rational use of drugs. The average number of analgesics prescribed per patient was 1.26. Similar finding was noted in Sarraf et al. [16] where it was 1.1 and by Sen and Bathini [1] where it was 1.39. The percentage of analgesics prescribed from EML was $18.18 \%$. This is because EML does not include diclofenac, tramadol, and combinations such as aceclofenac + serratiopeptidase and pentazocine + paracetamol which were commonly used in our study subjects.

The percentage of analgesics prescribed from NLEM was $90.84 \%$ in our study. This finding was consistent with essential drug list of our hospital. Similarly, in Agrawal et al. [14] study, 85.18\% drugs were prescribed from the National Model List of Essential Medicines, India. However, in Choudhury et al. [17] study, it was stated that $62.67 \%$ of analgesics complied with those from NLEMs whereas in Bhansali et al. [15] study, only $45.71 \%$ drugs were prescribed from the list. The higher percentage of drugs from the NLEM could be due to an effective and successful implementation of EML in our hospital. The primary purpose of NLEM is to promote rational use of medicines keeping in mind the important aspects of cost, safety, and efficacy. Furthermore, it promotes prescription by generic names [14].

In our study, diclofenac sodium was the most commonly used analgesic as parental and oral route (Table 3) which is consistent with the findings of Choudhury et al. [17] and Bhansali et al. [15]. Similarly, in Agrawal et al. [14] study, diclofenac was the most commonly used analgesic. As post-operative pain is one of the major problems after surgery, use of an analgesic has almost become mandatory following surgery. Diclofenac has been chosen both as mono and in combination with other drugs. It is a nonselective COX inhibitor and is effective in relieving inflammation induced moderate and severe pain. The advantage of diclofenac in postoperative pain is that it can be administered parenteral in initial postoperative period which can be converted to oral route later on. Nonopioid drugs have been shown to produce lesser side effects than opioid drugs and their use can decrease the requirement of opioid analgesic in the early post-operative period also [6].

The other common analgesics used in our study were paracetamol and tramadol (Table 3). Similarly, in Bhataia et al. [8] study, paracetamol and opioid analgesics such as tramadol were commonly used. Tramadol 
which acts on the central nervous system is mainly used as I.V in drip, to provide an immediate relief to the patients if the pain becomes unbearable [1].

About $13.76 \%$ of total drugs were FDCs. The most common FDC used in our study were T.aceclofenac 325mg+serratiopeptidase $15 \mathrm{mg}$ (5.04\%) and T.pentazocine $15 \mathrm{mg}$ + paracetamol $500 \mathrm{mg}$ (2.08\%) (Table 4). The advantage of FDCs is the lesser number of drug doses to be taken by the patient and an improved compliance. However, the FDC may not contain the required amount of individual drugs. The combination may not be synergistic, and it would only add to the cost of the therapy. About $80.28 \%$ and $75.53 \%$ of FDCs prescribed in our study were approved by DCGI and WHO, respectively. This denotes rational prescribing trend.

In Table 5, ATC-DDD classification of three most common AMAs and three most common analgesics is shown. The DDD is the assumed average maintenance dose per day for a drug used for its main indication in adults. The DDD does not necessarily reflect the recommended or actual dose used. The objective of ATC/DDD system is to serve as tool for drug utilization research, to favor improvement in drug use.

At resent, the American Society of Anesthesiologists Task Force on Acute Pain Management advocates the use of multimodal analgesia [18]. Multimodal analgesia is achieved by combining different analgesics that act by different pharmacological mechanisms and at different sites in the nervous system, resulting in additive, or synergistic analgesia with lesser adverse effects of sole administration of individual analgesics [19]. This approach recognizes the pathophysiology of surgical pain. It uses several agents to decrease the pain receptor activity and reduce the local hormone response to injury $[20,21]$. An example of multimodal analgesia is the use of regional anesthesia and analgesia to inhibit the neural conduction from the surgical site to the spinal cord and decrease spinal cord sensitization [22]. Another example is of local anesthetics that directly blocks pain receptor activity, antiinflammatory drugs can minimize the hormonal response to injury, and drugs such acetaminophen, ketamine, clonidine, dexmedetomidine, gabapentin, and pregabalin can produce analgesia by targeting specific neurotransmitters [20]. Hence, the target of providing maximum benefit with optimal pain control, limiting opioid use post-surgery and decreasing their adverse effects can be achieved through this modality of treatment.

\section{CONCLUSION}

This study portrays the prescription pattern for peri-operative pain focussing on the management of post-operative algesia. The measures to promote optimal analgesic use are encouraging multimodal analgesia to the patient whenever possible, introduction of a multidisciplinary team in hospital using simple techniques and simple instructions to prescribers and patients, creating awareness to patient regarding analgesic abuse, analgesic dependence, and tolerance as most of them are over the counter drugs and easily available and carrying out routine audits of the quality of patient care. It is necessary to determine the prevalence and severity of post-surgical pain and implementation of standardized pain evaluation and treatment protocols which improve post-operative patient care in the hospital setting.

\section{LIMITATIONS OF THE STUDY}

The limitations of the current study include the involvement of small number of patients which did not give complete overview among the different departments. Further studies involving different departments encompassing super-specialty and oncology surgical patients should be established.

\section{AUTHORS' CONTRIBUTIONS}

All authors have contributed equally in developing the concept of the study, data collection, data analysis, and drafting the manuscript.

\section{CONFLICTS OF INTEREST}

Declared none.

\section{AUTHORS FUNDING}

Nil.

\section{REFERENCES}

1. Sen S, Bathini P. Auditing analgesic use in post-operative setting in a teaching hospital. J Clin Diagn Res 2015;9:FC01.

2. Butterworth J, Mackey D, Wasnick J. Morgan and Mikhail's Clinical Anesthesiology. New York: Lange/McGraw-Hill; 2013.

3. Elvir-Lazo OL, White PF. Postoperative pain management after ambulatory surgery: Role of multimodal analgesia. Anesthesiol Clin 2010;28:217-24

4. White PF. What are the advantages of non-opioid analgesic techniques in the management of acute and chronic pain? Expert Opin Pharmacother 2017;18:329-33.

5. Macintyre PE, Scott DA, Schug SA, Visser EJ, Walker SM, editors. Acute Pain Management: Scientific Evidence. $3^{\text {rd }}$ ed. Melbourne: Australian and New Zealand College of Anaesthetists; 2010.

6. Kumarasingam T, Revathy S, Mukherjee D. Drug utilization pattern of analgesics among postoperative patients in a tertiary care hospital. Sch Res Library Pharm Lett 2014;6:40-6.

7. Roshini AA, Abishek S, Ashwini K, Manasa J, Siddiqui T. Prescribing patterns of analgesics in the post-operative period of surgical interventions. Indo Am J Pharm Res 2015;5:2555-9.

8. Bhataia S, Mathur S, Sankhla S, Kumar M, Sharma M. Auditing of prescription to study the drug utilization pattern in post-operative patients in general surgery wards: A study at a tertiary care hospital. Int J Pharm Biol Sci 2016;7:332-8

9. WHOCC Purpose of the ATC/DDD System. Available from: https:// www.whocc.no/atc_ddd_methodology/purpose_of_the_atc_ddd system.

10. Arshad M, Raghunandan M, Vasant RC, Fayazuddin M. Drug utilization study in post-operative patients in the surgery ward of a tertiary care teaching hospital in South India. Asian J Pharm Clin Res 2018;11:124-7.

11. Min Y, Tun T, Linn YH, Aye NN, Win NH. Utilization, availability of analgesics and quality of pain control for post-operative pain in surgical patients. Drugs Ther Perspect 2019;35:93-9.

12. Khan ML, Arain A, Qureshi FA. Patient's selection in limited resources a stimulus for improving care. PJS 2008;24:35-8.

13. Barawade S, Gursale S. A study of drug utilization pattern of analgesics in postoperative patients of tertiary care hospital. Med Pulse Int J Pharmacol 2017;1:28-32

14. Agrawal JM, Patel NM, Vaniya HV, Trivedi HR, Balat JD. Drug utilization study in post-operative patients in obstetrics and gynaecology ward of a tertiary care teaching hospital. J Clin Exp Res 2014;2:103-9.

15. Bhansali NB, Gosai TR, Dholaria NK, Suthar SD, Chacko J, Chavda DA, et al. Drug utilization study in post-operative patients in surgical ward of a tertiary hospital attached with medical college. Pharm Lett 2013;5:251-7.

16. Sarraf DP, Rauniar GP, Misra A. Drug utilization pattern in four major wards of a tertiary hospital in Eastern Nepal. Health Renaiss 2015;13:50-65.

17. Choudhury DK, Bezbaruah BK. Prescribing pattern of analgesics in orthopedic in-patient department at tertiary care hospital in Guwahati, Assam, Northeast India. Indian J Pharmacol 2016;48:377.

18. Ashburn MA, Caplan RA, Carr DB. Practice guidelines for acute pain management in the perioperative setting. An updated report by the American society of anesthesiologists task force on acute pain management. Anesthesiology 2004;100:1573-81.

19. Kehlet H, Dahl JB. The value of multimodal or balanced analgesia in the postoperative pain treatment. Anesth Analg 1993;77:1048-56.

20. Kodali BS, Oberoi J. Management of postoperative pain. In: Rosenquist EW, Doucette K, editors. Systematic Reviews and Metaanalyses. Waltham, MA: UpToDate; 2014.

21. American Society of Anesthesiologists Task Force on Acute Pain Management. Practice guidelines for acute pain management in the perioperative setting: An updated report by the American society of anesthesiologists task force on acute pain management. Anesthesiology 2012;116:248-73.

22. Buvanendran A, Kroin JS. Multimodal analgesia for controlling acute postoperative pain. Current opinion in Anesthesiology 2009;22:588-93. 